\title{
Protective Effect of Crocus sativus Stigma Extract and Crocin (trans-crocin 4) on Methyl Methanesulfonate-Induced DNA Damage in Mice Organs
}

\author{
Hossein Hosseinzadeh, ${ }^{1,2}$ Akram Abootorabi, ${ }^{2}$ and Hamid R. Sadeghnia ${ }^{3}$
}

This study was designed to examine the effect of aqueous extract of Crocus sativus stigmas (CSE) and crocin (trans-crocin 4) on methyl methanesulfonate (MMS)-induced DNA damage in multiple mice organs using comet assay. Adult male NMRI mice in different groups were treated with either physiological saline $(10 \mathrm{~mL} / \mathrm{Kg}$, intraperitoneal [ip]), CSE $(80 \mathrm{mg} / \mathrm{Kg}$, ip), crocin $(400 \mathrm{mg} / \mathrm{Kg}$, ip), MMS $(120 \mathrm{mg} / \mathrm{Kg}$, ip), and CSE (5, 20, and $80 \mathrm{mg} / \mathrm{Kg}$, ip) $45 \mathrm{~min}$ prior to MMS administration or crocin (50, 200, and $400 \mathrm{mg} / \mathrm{Kg}$, ip) $45 \mathrm{~min}$ prior to MMS administration. Mice were scarified about $3 \mathrm{~h}$ after each different treatment, and the alkaline comet assay was used to evaluate the effect of these compounds on DNA damage in different mice organs. The percent of DNA in the comet tail (\% tail DNA) was measured. A significant increase in the $\%$ tail DNA was seen in nuclei of different organs of MMS-treated mice. In control groups, no significant difference was found in the \% tail DNA between CSE- or crocin-pretreated and saline-pretreated mice. The MMS-induced DNA damage in CSEpretreated mice $(80 \mathrm{mg} / \mathrm{Kg})$ was decreased between 2.67-fold (kidney) and 4.48-fold (lung) compared to those of MMS-treated animals alone $(p<0.001)$. This suppression of DNA damage by CSE was found to be depended on the dose, which pretreatment with CSE $(5 \mathrm{mg} / \mathrm{Kg})$ only reduced DNA damage by $6.97 \%, 6.57 \%, 7.27 \%$, and $9.90 \%$ in liver, lung, kidney, and spleen, respectively ( $p>0.05$ as compared with MMS-treated group). In the same way, crocin also significantly decreased DNA damage by MMS (between 4.69-fold for liver and 6.55-fold for spleen, $400 \mathrm{mg} / \mathrm{Kg}$ ), in a dose-dependent manner. These data indicate that there is a genoprotective property in CSE and crocin, as revealed by the comet assay, in vivo.

\section{Introduction}

$\mathrm{C}$ ONSIDERABLE AMOUNT OF epidemiological evidence and laboratory investigations has shown a protective effect of diets rich in fruits and vegetables against cancer by inhibiting genotoxins and/or carcinogens through the biologically active plant secondary metabolites (Rogers et al., 1993; Ferguson, 1994; Ames, 2001). Therefore, assessment of their potential and understanding their probable mechanisms of action could be useful for better management of chemopreventive strategies.

Crocus sativus L., commonly known as saffron, is a perennial stemless herb that is widely cultivated in different parts of the world, especially Greece, India, Iran, and Spain. The major biologically active ingredients of saffron are crocins (which are glycoside derivatives of trans-crocetin), picrocrocin, and safranal (Tarantilis et al., 1995). Saffron is used in folk medicine as an anodyne, antidepressant, sedative, respiratory decongestant, anticatarrhal, expectorant, antispasmodic, eupeptic, stomachic, carminative, diaphoretic, gingival sedative, aphrodisiac, and emmenagogue (Rios et al., 1996; Abdullaev and Espinosa-Aguirre, 2004). Further, modern pharmacological studies have shown that saffron extract or its active constituents have learning- and memoryimproving properties (Abe and Saito, 2000; Pitsikas et al., 2007), anticonvulsant (Hosseinzadeh and Khosravan, 2002; Hosseinzadeh and Talebzadeh, 2005), antidepressant (Hosseinzadeh et al., 2004; Akhondzadeh et al., 2004), antiinflammatory (Hosseinzadeh and Younesi, 2002), antiischemic (Hosseinzadeh and Sadeghnia, 2005; Hosseinzadeh et al., 2008; Zheng et al., 2007), and antitumor effects (Abdullaev, 1993, 2002; Abdullaev and Espinosa-Aguirre, 2004). Radical scavenging, antioxidant activity, and promotion of the diffusivity of oxygen in different tissues were also reported for saffron extract or its bioactive constituents (Rios et al., 1996; Verma and Bordia, 1998; Assimopoulou et al., 2005; Kanakis et al., 2007a). Saffron extract also has chemopreventive and genoprotective effects and protects from genotoxin-induced oxidative stress in mice (Nair et al., 1995;

\footnotetext{
${ }^{1}$ Pharmaceutical Research Center, School of Pharmacy, Mashhad University of Medical Sciences, Mashhad, I.R. Iran.

${ }^{2}$ Department of Pharmacodynamy and Toxicology, School of Pharmacy, Mashhad University of Medical Sciences, Mashhad, I.R. Iran.

${ }^{3}$ Department of Pharmacology, Faculty of Medicine, Mashhad University of Medical Sciences, Mashhad, I.R. Iran.
} 
Premkumar et al., 2001; Abdullaev et al., 2002; Premkumar et al., 2003).

Recently, we have found that safranal, a constituent of saffron, could exert protective effect against methyl methanesulfonate (MMS)-induced DNA damage in mice organs (Hosseinzadeh and Sadeghnia, 2007). In this study we designed to examine the influence of aqueous extract of $C$. sativus stigmas (CSE) and crocin (trans-crocin 4), another constituent of saffron, on MMS-induced DNA damage in multiple mice organs (liver, lung, kidney, and spleen), using alkaline single gel electrophoresis (SCGE) or comet assay.

\section{Materials and Methods}

\section{Animals}

Adult male NMRI mice weighing 25-30 g were used throughout the study. All of them were kept in the same room under a constant temperature $\left(22 \pm 2^{\circ} \mathrm{C}\right)$ and illuminated 7:00 a.m. to 7:00 p.m., with food pellets and water available ad libitum. The experiment was approved by the University's Ethics Committee for Animal Use.

\section{Chemicals}

Chemicals were obtained from the following sources: low melting point (LMP) agarose from Biogen (Mashhad, I.R. Iran); normal melting point (NMP) agarose from Fermentas (Glen Burnie, MD); crocin (trans-crocin 4) from Fluka (St. Gallen, Switzerland); and sodium hydroxide $(\mathrm{NaOH})$, sodium chloride $(\mathrm{NaCl})$, ethylenediaminetetraacetic acid disodium salt $\left(\mathrm{Na}_{2} \mathrm{EDTA}\right)$, Tris (hydroxymethyl) aminomethane (Trizma base), $t$-octylphenoxypoly-ethoxyethanol (Triton X-100), dimethylsulfoxide (DMSO), sodium lauroylsarcosinate (sarkosyl, SLS), MMS, and methanol from Merck (Darmstadt, Germany). LMP and NMP agarose were diluted in physiological saline to $0.5 \%$ and $1 \%$, respectively.

\section{Preparation of aqueous saffron extract}

C. sativus L. stigmas were collected from Ghaen (Khorasan Province, northeast of Iran). In the maceration method, $1 \mathrm{~g}$ of stigma was macerated in $800 \mathrm{~mL}$ distilled water and gently shaken for 3 days. The mixture was subsequently filtered, and concentrated under reduced pressure at $35^{\circ} \mathrm{C}$. The extract contains $1.97 \%$ of trans-crocin 4 (Modaghegh et al., 2008).

\section{Treatment and organ preparation}

Ten groups of male mice were used for this experiment (for each treatment group, $n=5-7)$. The animals in different groups were received the following chemicals: physiological saline $(10 \mathrm{~mL} / \mathrm{Kg}$, ip), CSE $(80 \mathrm{mg} / \mathrm{Kg}$, ip), crocin $(400$ $\mathrm{mg} / \mathrm{Kg}$ ), MMS (120 mg/Kg, ip), CSE (5, 20, and $80 \mathrm{mg} / \mathrm{Kg}$, ip) $45 \mathrm{~min}$ prior to MMS administration, and crocin (50, 200, and $400 \mathrm{mg} / \mathrm{Kg}$, ip) $45 \mathrm{~min}$ prior to MMS administration. About $3 \mathrm{~h}$ after injection, the animals were killed by cervical dislocation, and four organs (liver, lung, spleen, and kidney) were removed. Changes in size, color, and texture of organs were examined. After weighing the organs, they were minced, suspended at a concentration of $0.5 \mathrm{~g} / \mathrm{mL}$ in chilled homogenizing buffer containing $0.075 \mathrm{M} \mathrm{NaCl}$ and $0.024 \mathrm{M} \mathrm{Na}_{2} \mathrm{ED}$ TA ( $\mathrm{pH} 7.5$ ), and then homogenized gently at 500-800 rpm in ice. To obtain nuclei, the homogenate was centrifuged at $700 \mathrm{~g}$ for $10 \mathrm{~min}$ at $0^{\circ} \mathrm{C}$, and the precipitate was resuspended in chilled homogenizing buffer at $0.5 \mathrm{~g} / \mathrm{mL}$ and allowed to settle; precipitated clumps were then removed. Doses and times were selected based on the preliminary studies as well as literature-reported values (Sasaki et al., 1997a, 1997b; Tsuda et al., 2000; Sekihashi et al., 2002).

\section{Slide preparation and alkaline SCGE assay}

The in vivo alkaline SCGE assay was conducted based on the method described by Sasaki et al. (1997a) with some modifications. One hundred microliters of NMP agarose was quickly layered on conventional slides, the slides were covered with a cover slip, and then the slides were placed on ice to allow agarose to gel. Five microliters of the nucleus suspension, prepared as above, was mixed with $75 \mu \mathrm{L}$ LMP agarose, and the mixture was quickly layered over the NMP agarose layer after removal of the cover slip. Finally, another layer of LMP agarose was added on top. The slides were immersed immediately in a chilled lysing solution $(\mathrm{pH} 10)$ made up of $2.5 \mathrm{M} \mathrm{NaCl}, 100 \mathrm{mM} \mathrm{Na}{ }_{2}$ EDTA, $10 \mathrm{mM}$ Trizma, $1 \%$ sarkosyl, $10 \%$ DMSO, and 1\% Triton X-100, and kept at $0^{\circ} \mathrm{C}$ in the dark overnight. Then, the slides were placed on a horizontal gel electrophoresis platform and covered with a chilled alkaline solution made up of $300 \mathrm{mM} \mathrm{NaOH}$ and $1 \mathrm{mM} \mathrm{Na} \mathrm{F}_{2}$ EDTA ( $\mathrm{pH} 13$ ). They were left in the solution in the dark at $0^{\circ} \mathrm{C}$ for $40 \mathrm{~min}$, and then electrophoresed at $0^{\circ} \mathrm{C}$ in the dark for $30 \mathrm{~min}$ at $25 \mathrm{~V}$ and approximately $300 \mathrm{~mA}$. The slides were rinsed gently three times with $400 \mathrm{mM}$ Trizma solution (adjusted to $\mathrm{pH} 7.5$ by $\mathrm{HCl}$ ) to neutralize the excess alkali, stained with $50 \mu \mathrm{L}$ of $20 \mu \mathrm{g} / \mathrm{mL}$ ethidium bromide, and covered with a cover slip.

\section{Examination of the nuclei and statistical analysis}

One hundred nuclei per organ from each animal (50 nuclei on one slide) were examined and photographed through a fluorescence microscope (Nikon, Kyoto, Japan) at $400 \times$ magnification equipped with an excitation filter of 520$550 \mathrm{~nm}$ and a barrier filter of $580 \mathrm{~nm}$.

Undamaged cells resemble an intact nucleus without a tail, and damaged cells have the appearance of a comet. The percent of DNA in the comet tail (\% tail DNA), which is an estimate of DNA damage, was measured using a computerized image analysis software (CASP software). Statistical analysis was performed using one-way ANOVA followed by Tukey-Kramer post hoc test for multiple comparisons. The $p$-values less than 0.05 were considered to be statistically significant.

\section{Results}

In this study, \% tail DNA was measured as an indicator of DNA damage. A significant increase in the \% tail DNA was seen in nuclei of different organs of MMS-treated mice, as compared to those of saline-treated animals $(p<0.001$; Figs. 1 and 2). In control groups, no significant difference was found in the \% tail DNA between CSE- or crocin-pretreated and saline-pretreated mice. The MMS-induced DNA damage in CSE-pretreated mice $(80 \mathrm{mg} / \mathrm{Kg}$ ) was decreased between 2.67-fold (kidney) and 4.48-fold (lung) as compared to that of MMS-treated animals alone $(p<0.001$; Fig. 1A-D). This 


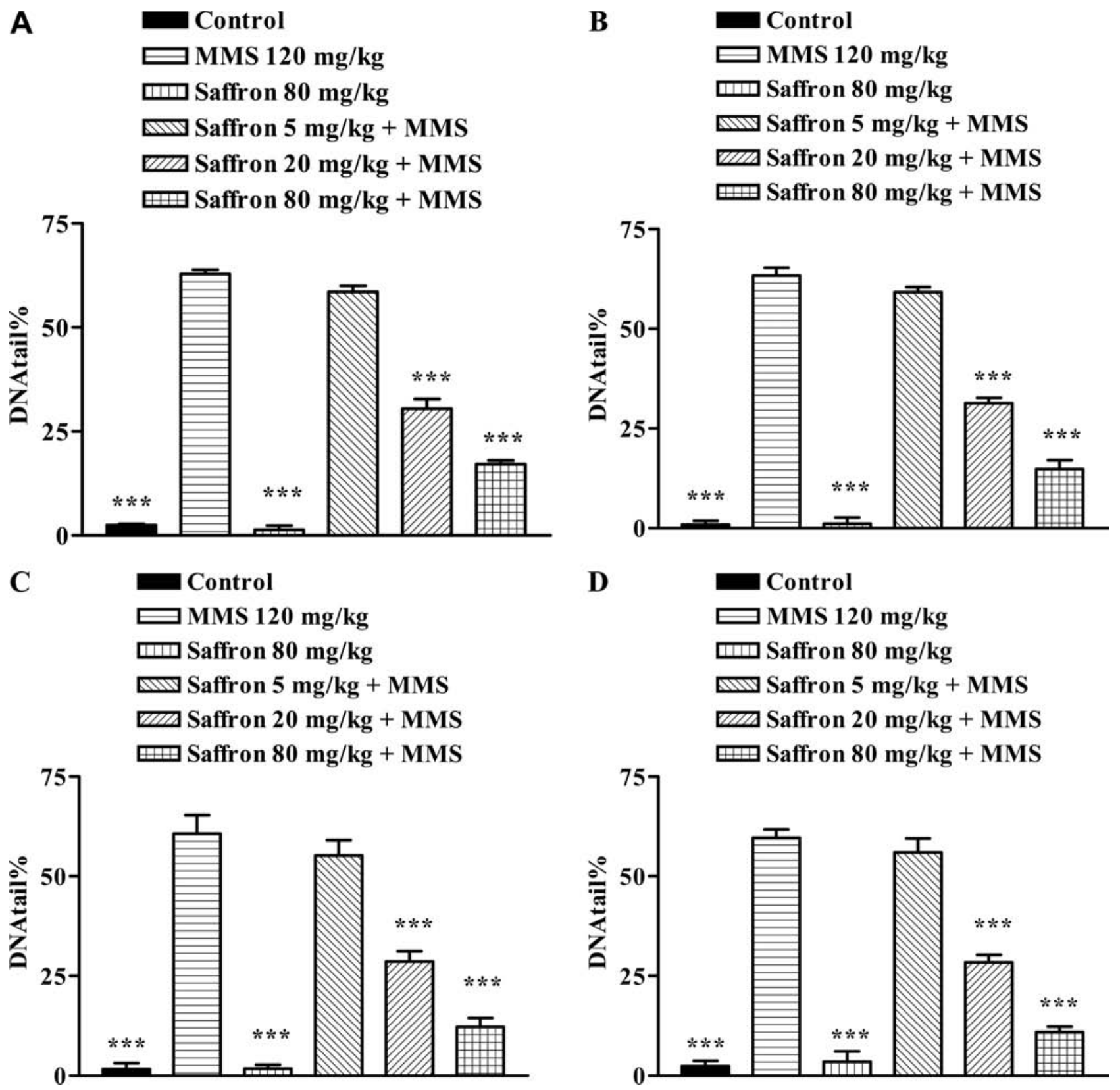

FIG. 1. (A) Effect of saffron aqueous extract on DNA damage induced by MMS in mouse liver. CSE was administered 45 min prior to MMS injection, ip. Values are mean \pm SEM of 5-7 mice. ${ }^{* * *} p<0.001$ as compared with MMS-treated mice (oneway ANOVA followed by Tukey-Kramer test). (B) Effect of saffron aqueous extract on DNA damage induced by MMS in mouse lung. CSE was administered $45 \mathrm{~min}$ prior to MMS injection, ip. Values are mean \pm SEM of $5-7$ mice. ${ }^{* * *} p<0.001$ as compared with MMS-treated mice (one-way ANOVA followed by Tukey-Kramer test). (C) Effect of saffron aqueous extract on DNA damage induced by MMS in mouse kidney. CSE was administered $45 \mathrm{~min}$ prior to MMS injection, ip. Values are mean \pm SEM of 5-7 mice. ${ }^{* * *} p<0.001$ as compared with MMS-treated mice (one-way ANOVA followed by Tukey-Kramer test). (D) Effect of saffron aqueous extract on DNA damage induced by MMS in mouse spleen. CSE was administered 45 min prior to MMS injection, ip. Values are mean \pm SEM of five mice. ${ }^{* * *} p<0.001$ as compared with MMS-treated mice (one-way ANOVA followed by Tukey-Kramer test).

suppression of DNA damage by CSE was found to be depended on the dose, which pretreatment with CSE $(5 \mathrm{mg} / \mathrm{Kg})$ only reduced DNA damage by $6.97 \%, 6.57 \%$, $7.27 \%$, and $9.90 \%$ in liver, lung, kidney, and spleen, respectively ( $p>0.05$ as compared with MMS-treated group; Fig. 1A-D). In the same way, crocin also significantly decreased DNA damage by MMS (between 4.69-fold for liver and 6.55-fold for spleen, $400 \mathrm{mg} / \mathrm{Kg}$ ), in a dose-dependent manner (Fig. 2A-D).

\section{Discussion}

Recently, considerable attention has been focused on the use of natural compounds as chemopreventive/chemoprotective 
A

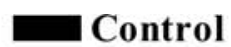

$\sqsupseteq M M S 120 \mathrm{mg} / \mathrm{kg}$

Crocin $400 \mathrm{mg} / \mathrm{kg}$

Crocin $50 \mathrm{mg} / \mathrm{kg}+$ MMS

mas Crocin $200 \mathrm{mg} / \mathrm{kg}+$ MMS
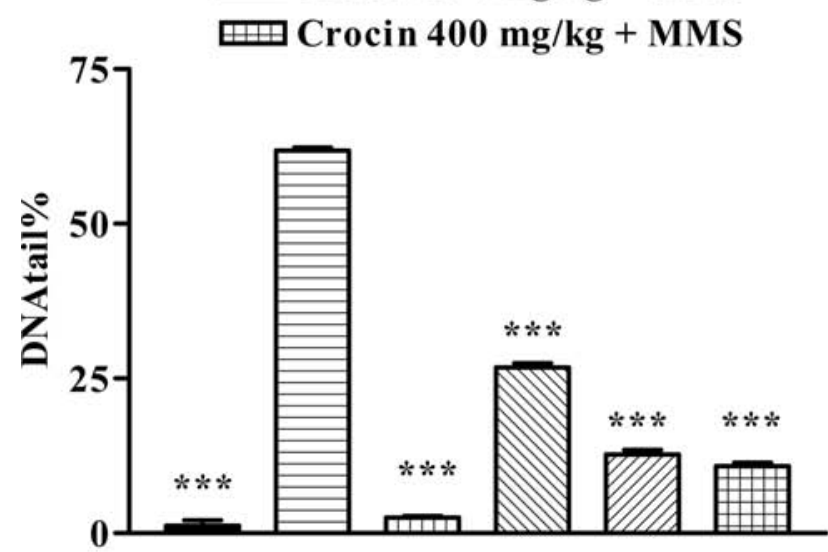

C

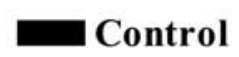

$\sqsupseteq M M S 120 \mathrm{mg} / \mathrm{kg}$

Crocin $400 \mathrm{mg} / \mathrm{kg}$

Crocin $50 \mathrm{mg} / \mathrm{kg}+$ MMS

mod Crocin $200 \mathrm{mg} / \mathrm{kg}+$ MMS

Crocin $400 \mathrm{mg} / \mathrm{kg}+$ MMS

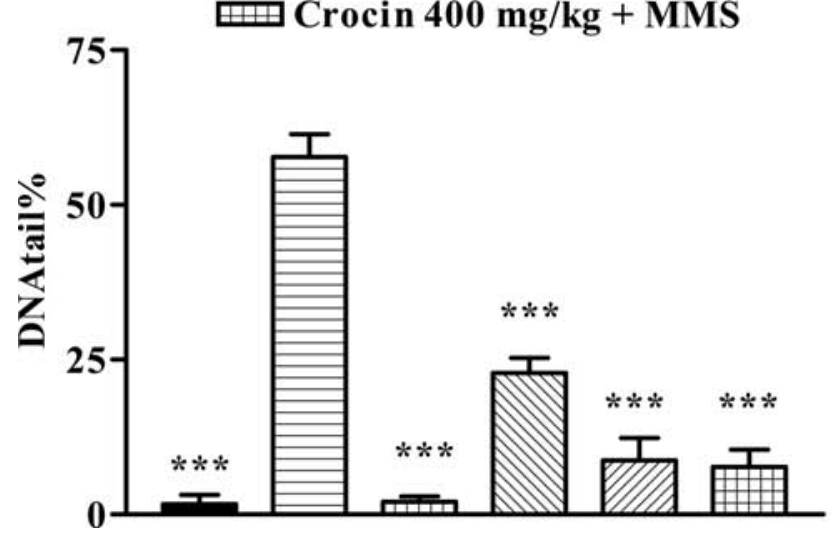

B

Control

$\sqsupseteq M M S 120 \mathrm{mg} / \mathrm{kg}$

Crocin $400 \mathrm{mg} / \mathrm{kg}$

Crocin $50 \mathrm{mg} / \mathrm{kg}+$ MMS

mos Crocin 200 mg/kg + MMS

Crocin $400 \mathrm{mg} / \mathrm{kg}+$ MMS

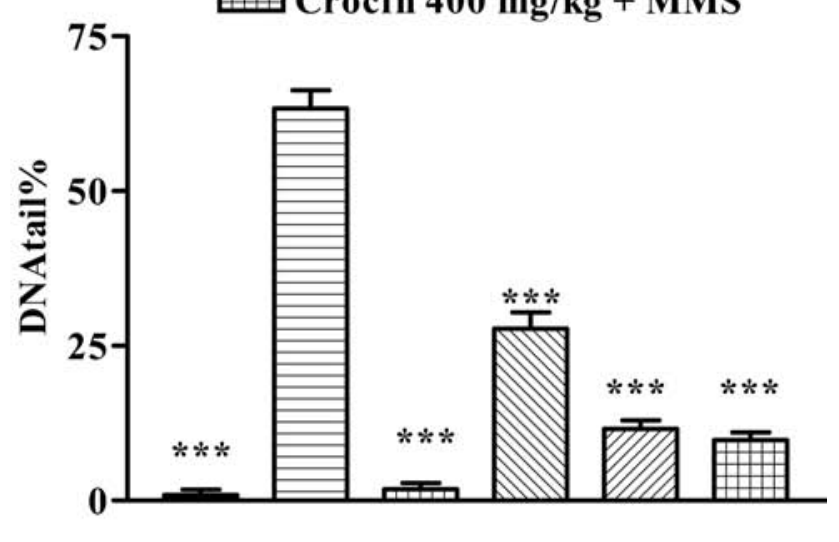

D

Control

띠 MMS $120 \mathrm{mg} / \mathrm{kg}$

$\square$ Crocin $400 \mathrm{mg} / \mathrm{kg}$

Crocin $50 \mathrm{mg} / \mathrm{kg}+$ MMS

T20 Crocin $200 \mathrm{mg} / \mathrm{kg}+$ MMS

Crocin $400 \mathrm{mg} / \mathrm{kg}+$ MMS

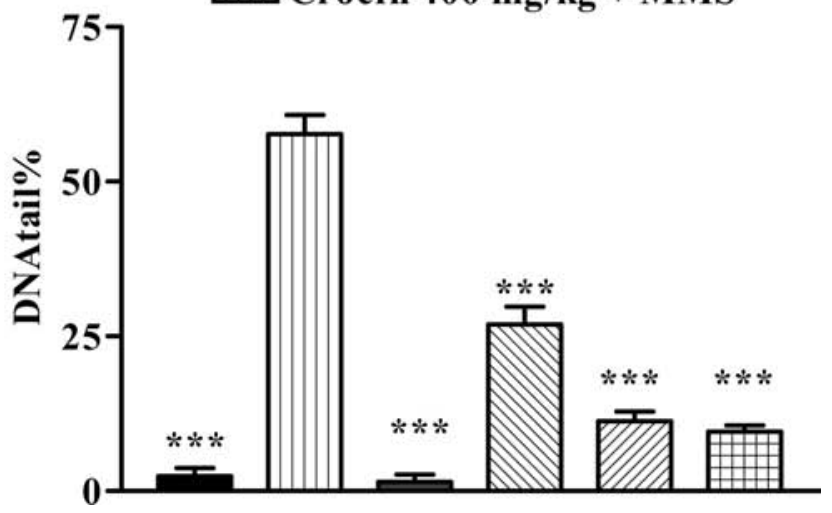

FIG. 2. (A) Effect of crocin on DNA damage induced by MMS in mouse liver. Crocin was administered 45 min prior to MMS injection, ip. Values are mean \pm SEM of 5-7 mice. ${ }^{* * *} p<0.001$ as compared with MMS-treated mice (one-way ANOVA followed by Tukey-Kramer test). (B) Effect of crocin on DNA damage induced by MMS in mouse lung. Crocin was administered $45 \mathrm{~min}$ prior to MMS injection, ip. Values are mean \pm SEM of 5-7 mice. ${ }^{* * *} p<0.001$ as compared with MMStreated mice (one-way ANOVA followed by Tukey-Kramer test). (C) Effect of crocin on DNA damage induced by MMS in mouse kidney. Crocin was administered $45 \mathrm{~min}$ prior to MMS injection, ip. Values are mean \pm SEM of $5-7$ mice. ${ }^{* * *} p<0.001$ as compared with MMS-treated mice (one-way ANOVA followed by Tukey-Kramer test). (D) Effect of crocin on DNA damage induced by MMS in mouse spleen. Crocin was administered $45 \mathrm{~min}$ prior to MMS injection, ip. Values are mean \pm SEM of five mice. ${ }^{* * *} p<0.001$ as compared with MMS-treated mice (one-way ANOVA followed by Tukey-Kramer test).

agents. Because of a strong correlation between genomic damage and carcinogenesis (Hoeijmakers, 2001), understanding the antigenotoxic potential of these compounds should be useful in cancer chemopreventive therapy.

There are two major findings in our study. First, no considerable DNA damage was seen in mice pretreated with relatively high doses of CSE and crocin, as revealed by comet assay. Second, pretreatment with CSE and crocin significantly suppressed MMS-induced DNA damage in multiple mice organs, in a dose-dependent manner. Although all doses of crocin significantly attenuated DNA damage induced by MMS, there was also a significant difference $(p<0.001)$ between pretreatment with the low dose $(50 \mathrm{mg} / \mathrm{Kg})$ and high dose $(200 \mathrm{mg} / \mathrm{Kg})$ of crocin, which means that the protective 
effect of the treatment with lower doses of crocin against MMS-induced genotoxicity cannot be postulated.

The results of the present study, however, are consistent with previous findings. It has been reported that saffron or its ingredients such as crocin and dimethylcrocin are not mutagenic or genotoxic (Salomi et al., 1991a; Abdullaev et al., 2002, 2003). Premkumar et al. also showed that saffron aqueous extract protects from genotoxicity as well as genotoxins-induced oxidative stress in mice (Premkumar et al., 2001, 2003, 2006). In these studies, oral pretreatment with aqueous saffron extract $(20,40$, and $80 \mathrm{mg} / \mathrm{Kg})$ for 5 consecutive days significantly inhibited the genotoxicity of antitumor drugs (cyclophosphamide, mitomycin C, and cisplatin), in vivo, as revealed by micronucleus and comet assay. It was suggested that saffron could exert its antigenotoxic and chemopreventive effects by the modulation of antioxidants and/or detoxification systems (Premkumar et al., 2001, 2006). It was also reported that crocetin could significantly inhibit the genotoxic effects and neoplastic transformations of C3H1OT1/2 cells by benzo(a)pyrene (Chang et al., 1996). An inhibitory effect of safranal on MMS-induced genotoxicity has also been shown in multiple mice organs (Hosseinzadeh and Sadeghnia, 2007). Therefore, safranal may also contribute to the preventive effect of saffron against MMSinduced DNA damage.

Several hypotheses may explain the attenuation of MMSinduced genotoxicity by CSE and crocin. A direct interaction with nucleic acids such as DNA and thereby protecting them from harmful damages were reported for crocin, crocetin, dimethylcrocin, and safranal, in vitro (Bathaie et al., 2007; Kanakis et al., 2007b, 2007c). It could be postulated that saffron decreases DNA damage by protecting DNA nucleophilic sites.

It is documented that chemopreventive agents can exert their antimutagenic/anticarcinogenic effects via several mechanism such as inhibiting the carcinogen activation, enhancing detoxification of carcinogenic agents, quenching reactive oxygen species or tapping of electrophiles, inhibition of cell replication, modulation of DNA metabolism and repair, control of gene expression (like inhibition of oncogene expression), influencing of apoptosis, and inhibition of tumor promotion or progression (De Flora, 1998). Among the detoxification mechanisms, glutathione (GSH) and its related enzymes have a central role (Ketterer, 1988; Franco et al., 2007). It is generally believed that agents increasing the GSH pool and inducing its related enzymes (such as GSH peroxidase, GSH reductase, and GSH -S-transferase) could inhibit the genotoxicity and carcinogenicity of toxic agents.

The protective effects of saffron and crocin observed in the present study may be related to its antioxidant and radical scavenger properties. Saffron and crocin may also decrease the MMS-induced genotoxicity by enhancing the systems involve in detoxification and mutagen/carcinogen inactivation. It has been shown that antioxidants reduced chemically induced carcinogenesis (Khan et al., 2008) and inhibited DNA lesions induced by alkylating agents such as MMS (Kaya, 2003; Arranz et al., 2007). Saffron and its carotenoids scavenge free radicals and thereby may protect cells from oxidative stress (Bors et al., 1982; Abdullaev, 1993; Nair et al., 1995; Rios et al., 1996; Pham et al., 2000; Assimopoulou et al., 2005). Recently, Papandreou et al. (2006) showed that CSE and its crocin constituents possess good antioxidant prop- erties, and inhibit amyloid $\beta$-peptide (A $\beta$ ) fibrils aggregation in a concentration- and time-dependent manner, in vitro. Ameliorating effects of saffron on cisplatin-induced toxicity and changes in enzyme activities have also been reported (Nair et al., 1991b; El Daly, 1998). It is known that crocins and crocetin decrease the aflatoxin $B_{1}$ and dimethylnitrosamineinduced hepatotoxicity and protects rat primary hepatocytes against oxidative damage (Lin and Wang, 1986; Wang et al., 1991a, 1991b; Tseng et al., 1995).

Reduction of lipid peroxidation, improving of total antioxidant capacity, total thiol contents, and GSH pool, as well as antioxidant enzyme activities such as superoxide dismutase, catalase, and GSH-related enzymes were reported for saffron, crocin, and safranal following ischemia-reperfusion injury (Hosseinzadeh and Sadeghnia, 2005; Hosseinzadeh et al., 2005; Saleem et al., 2006; Hosseinzadeh et al., 2008; Zheng et al., 2007). The modifying effects of saffron and its carotenoids on antioxidant enzymatic activities have also been shown in other experimental models (Premkumar et al., 2001; Premkumar et al., 2003; Shen and Qian, 2006). Moreover, crocin and other carotenoids from saffron prevent the death of rat pheochromocytoma (PC-12) cells, apoptotic morphological changes, and DNA fragmentation induced by tumor necrosis factor (TNF)- $\alpha$ and serum/glucose deprivation by its antioxidant effects and increasing GSH synthesis (Soeda et al., 2001; Ochiai et al., 2004a, 2004b, 2007).

There are several reports about chemopreventive and tumoricidal properties of saffron or its constituents, in vivo and in vitro (Salomi et al., 1991b; Nair et al., 1991a; Nair et al., 1994, 1995; Escribano et al., 1996; Abdullaev, 2002; Abdullaev et al., 2002; Abdullaev and Espinosa-Aguirre, 2004; Das et al., 2004; Chryssanthi et al., 2007). Abdullaev and Frenkel also showed that saffron could exert inhibitory effect on cellular DNA and RNA synthesis, but not on protein synthesis (Abdullaev and Frenkel, 1992a, 1992b). Cancer chemopreventive as well as antitumor activities were also reported for crocins and crocetin derivatives in different assay systems (Tarantilis et al., 1994; Wang et al., 1995; Escribano et al., 1996; Konoshima et al., 1998; Garcia-Olmo et al., 1999; Aung et al., 2007).

Another possibility is complex formation and inactivation of the alkylating agent by CSE and crocin, which were classified as desmutagenicity effects according to Kada and coworkers (Morita et al., 1978; Kada, 1983).

MMS is a monofunctional alkylating agent that interacts mainly with N-7 guanosine or N-3 adenosine and induces DNA lesions after the treatment. The most DNA lesions detected have the character of ALS, and true SSB represented only a minor fraction (Dipple, 1995; Horvathova et al., 1998). These DNA lesions are mainly processed via base excision repair (BER), a mechanism that is responsible for the removal of several classes of damage from DNA employing in early step-specific glycosylases, each recognizing and removing a subset of base damage. $\mathrm{N}$-alkylpurines are removed from DNA by BER via $N$-alkylpurine-DNA glycosylases (APDG) (Lindahl et al., 1997). CSE and crocin may affect the MMSinduced genotoxicity by enhancing BER through increasing the APDG activity or expression.

Taking together, the findings of the present study and other previous observations indicate that saffron extract and its crocin constituents can inhibit the genotoxicity/ carcinogenicity of chemicals with various mechanisms of 
action, which should be investigated further using different in vitro system assays and different experimental designs.

In conclusion, the results of the present study showed that aqueous extract of CSE and crocin clearly repressed the genotoxic potency of MMS, as measured by the comet assay, in different mice organs.

\section{Acknowledgment}

The authors are thankful to the Research Council, Mashhad University of Medical Sciences, for financial support.

\section{References}

Abdullaev, F.I. (1993). Biological effects of saffron. Biofactors 4, 83-86.

Abdullaev, F.I. (2002). Cancer chemopreventive and tumoricidal properties of saffron (Crocus sativus). Exp Biol Med 227, 20-25. Abdullaev, F.I., Caballero-Ortega, H., Riveron-Nigrete, L., Pereda-miranda, R., Rivera-Luna, R., Manuel Hernandez, J., Perez-Lopez, I., and Espinosa-Aguirre, J.J. (2002). In vitro evaluation of chemopreventive potential of saffron. Rev Invest Clin 54, 430-436.

Abdullaev, F.I., and Espinosa-Aguirre, J.J. (2004). Biomedical properties of saffron and its potential use in cancer therapy and chemoprevention trials. Cancer Detect Prev 28, 426-432.

Abdullaev, F.I., and Frenkel, G.D. (1992a). Effect of saffron on cell colony formation and cellular nucleic acid and protein synthesis. Biofactors 3, 201-204.

Abdullaev, F.I., and Frenkel, G.D. (1992b). The effect of saffron on intracellular DNA, RNA and protein synthesis in malignant and non-malignant human cells. Biofactors 4, 43-45.

Abdullaev, F.I., Riveron-Negrete, L., Caballero-Ortega, H., Manuel Hernandez, J., Perez-Lopez, I., Pereda-Miranda, R., and Espinosa-Aguirre, J.J. (2003). Use of in vitro assays to assess the potential antigenotoxic and cytotoxic effects of saffron (Crocus satious L.). Toxicol In Vitro 17, 731-736.

Abe, K., and Saito, H. (2000). Effects of saffron extract and its constituent crocin on learning behaviour and long-term potentiation. Phytother Res 14, 149-152.

Akhondzadeh, S., Fallah-Pour, H., Afkham, K., Jamshidi, A.H., and Khalighi-Cigaroudi, F. (2004). Comparison of Crocus sativus $\mathrm{L}$. and imipramine in the treatment of mild to moderate depression: a pilot double-blind randomized trial. BMC Complement Altern Med 4, 1-5.

Ames, B.N. (2001). DNA damage from micronutrient deficiencies is likely to be a major cause of cancer. Mutat Res 475, 7-20.

Arranz, N., Haza, A.I., Garcia, A., Rafter, J., and Morales, P. (2007). Protective effect of vitamin C towards N-nitrosamineinduced DNA damage in the single-cell gel electrophoresis (SCGE)/HepG2 assay. Toxicol In Vitro 21, 1311-1317.

Assimopoulou, A.N., Sinakos, Z., and Papageorgiou, V.P. (2005). Radical scavenging activity of Crocus sativus L. extract and its bioactive constituents. Phytother Res 19, 997-1000.

Aung, H.H., Wang, C.Z., Ni, M., Fishbein, A., Mehendale, S.R., Xie, J.T., Shoyama, C.Y., and Yuan, C.S. (2007). Crocin from Crocus sativus possesses significant anti-proliferation effects on human colorectal cancer cells. Exp Oncol 29, 175-180.

Bathaie, S.Z., Bolhasani, A., Hoshyar, R., Ranjbar, B., Sabouni, F., and Moosavi-Movahedi, A.A. (2007). Interaction of saffron carotenoids as anticancer compounds with ctDNA, Oligo (dG.dC) 15 and Oligo (dA.dT) 15. DNA Cell Biol 26, 533-540.
Bors, W., Saran, M., and Michel, C. (1982). Radical intermediates involved in the bleaching of the carotenoid crocin. Hydroxyl radicals, superoxide anions and hydrated electrons. Int J Radiat Biol Relat Stud Phys Chem Med 41, 493-501.

Chang, V.C., Lin, Y.L., Lee, M.J., Show, S.J., and Wang, C.J. (1996). Inhibitory effect of crocetin on benzo(a)pyrene genotoxicity and neoplastic transformation in C3H1OT1/2 cells. Anticancer Res 765, 3603-3608.

Chryssanthi, D.G., Lamari, F.N., Iatrou, G., Pylara, A., Karamanos, N.K., and Cordopatis, P. (2007). Inhibition of breast cancer cell proliferation by style constituents of different Crocus species. Anticancer Res 27, 357-362.

Das, I., Chakrabarty, R.N., and Das, S. (2004). Saffron can prevent chemically induced skin carcinogenesis in Swiss albino mice. Asian Pac J Cancer Prev 4, 70-76.

De Flora, S. (1998). Mechanisms of inhibitors of mutagenesis and carcinogenesis. Mutat Res 402, 151-158.

Dipple, A. (1995). DNA adducts of chemical carcinogens. Carcinogenesis 16, 437-441.

El Daly, E.S. (1998). Protective effect of cysteine and vitamin E, Crocus sativus and Nigella sativa extracts on cisplatin-induced toxicity in rats. J Pharm Belg 53, 87-95.

Escribano, J., Alonso, G.L., Coca-Prados, M., and Fernandez, J.A. (1996). Crocin, safranal and picrocrocin from saffron (Crocus sativus L.) inhibit the growth of human cancer cells in vitro. Cancer Lett 100, 23-30.

Ferguson, L.R. (1994). Antimutagens as cancer chemopreventive agents in the diet. Mutat Res 307, 395-410.

Franco, R., Schonveld, O.J., Pappa, A., and Panayiotidis, M.I. (2007). The central role of glutathione in the pathophysiology of human diseases. Arch Physiol Biochem 113, 234-258.

Garcia-Olmo, D.C., Riese, H.H., Escribano, J., Ontanon, J., Fernandez, J.A., Atienzar, M., and Garcia-Olmo, D. (1999). Effects of long term treatment of colon adenocarcinoma with crocin, a carotenoid from saffron (Crocus sativus): an experimental study in the rat. Nutr Cancer 35, 120-126.

Hoeijmakers, J.H. (2001). Genome maintenance mechanisms for preventing cancer. Nature 411, 366-374.

Horvathova, E., Slamenova, D., Hlincikova, L., Mandal, T.K., Gabelova, A., and Collins, A.R. (1998). The nature and origin of DNA single-strand breaks determined with the comet assay. Mutat Res 409, 163-171.

Hosseinzadeh, H., Karimi, G., and Niapoor, M. (2004). Antidepressant effects of Crocus sativus stigma extracts and its constituents, crocin and safranal, in mice. Acta Hortic 650, 435-445.

Hosseinzadeh, H., and Khosravan, V. (2002). Anticonvulsant effects of aqueous and ethanolic extracts of Crocus sativus L. stigmas in mice. Arch Iran Med 5, 44-47.

Hosseinzadeh, H., Modaghegh, M.H., and Saffari, Z. (2008). Crocus Sativus L. (saffron) extract and its active constituents (crocin and safranal) on ischemia-reperfusion in rat skeletal muscle. eCAM (in press).

Hosseinzadeh, H., and Sadeghnia, H.R. (2005). Safranal, a constituent of Crocus satious (saffron), attenuated cerebral ischemia induced oxidative damage in rat hippocampus. J Pharm Pharm Sci 8, 394-399.

Hosseinzadeh, H., and Sadeghnia, H.R. (2007). Effect of safranal, a constituent of Crocus sativus (saffron), on methyl methanesulfonate (MMS)-induced DNA damage in mouse organs: an alkaline single-cell gel electrophoresis (comet) assay. DNA Cell Biol 26, 841-846.

Hosseinzadeh, H., Sadeghnia, H.R., Ziaee, T., and Danaee, A. (2005). Protective effect of aqueous saffron extract (Crocus 
sativus L.) and crocin, its active constituent, on renal ischemiareperfusion-induced oxidative damage in rats. J Pharm Pharm Sci 8, 387-393.

Hosseinzadeh, H., and Talebzadeh, F. (2005). Anticonvulsant evaluation of safranal and crocin from Crocus sativus in mice. Fitoterapia 76, 722-724.

Hosseinzadeh, H., and Younesi, H.M. (2002). Antinociceptive and anti-inflammatory effects of Crocus sativus L. stigma and petal extracts in mice. BMC Pharmacol 2, 1-8.

Kada, T. (1983). Environmental and biological factors suppressing induction of mutagens. Toxicol Forum 6, 580-589.

Kanakis, C.D., Tarantilis, P.A., Tajmir-Riahi, H.A., and Polissiou, M.G. (2007a). Crocetin, dimethylcrocetin, and safranal bind human serum albumin: stability and antioxidative properties. J Agric Food Chem 55, 970-977.

Kanakis, C.D., Tarantilis, P.A., Tajmir-Riahi, H.A., and Polissiou, M.G. (2007b). DNA interaction with saffron's secondary metabolites safranal, crocetin, and dimethylcrocetin. DNA Cell Biol 26, 63-70.

Kanakis, C.D., Tarantilis, P.A., Tajmir-Riahi, H.A., and Polissiou, M.G. (2007c). Interaction of tRNA with safranal, crocetin, and dimethylcrocetin. J Biomol Struct Dyn 24, 537-546.

Kaya, B. (2003). Antigenotoxic effect of ascorbic acid on mutagenic dose of three alkylating agents. Turk J Biol 27, 241-246.

Ketterer, B. (1988). Protective role of glutathione and glutathione transferases in mutagenesis and carcinogenesis. Mutat Res 202, 343-361.

Khan, N., Afaq, F., and Mukhtar, H. (2008). Cancer chemoprevention through dietary antioxidants: progress and promise. Antioxid Redox Signal 10, 475-510.

Konoshima, T., Takasaki, M., Tokuda, H., Morimoto, S., Tanaka, H., Kawata, E., Xuan, L.J., Saito, H., Sugiura, M., Molnar, J., and Shoyama, Y. (1998). Crocin and crocetin derivatives inhibit skin tumor promotion in mice. Phytother Res 12, 400404.

Lin, J.K., and Wang, C.J. (1986). Protection of crocin dyes on the acute hepatic damage induced by aflatoxin $B_{1}$ and dimethylnitrosamine in rats. Carcinogenesis 7, 595-599.

Lindahl, T., Karran, P., and Wood, R.D. (1997). DNA excision repair pathways. Curr Opin Genet Dev 7, 158-169.

Modaghegh, M.H., Shahabian, M., Esmaeili, H.A., Rajbai, O., and Hosseinzadeh, H. (2008). Safety evaluation of saffron, Crocus sativus, tablet in healthy volunteers. Phytomedicine (In press).

Morita, K., Hara, M., and Kada, T. (1978). Studies on natural desmutagenic screening for vegetable and fruit factors active in inactivation of mutagenic pyrolysis products from amino acids. Agric Biol Chem 42, 1235-1238.

Nair, S.C., Kurumboor, S.K., and Hasegawa, J.H. (1995). Saffron chemoprevention in biology and medicine: a review. Cancer Biother 10, 257-264.

Nair, S.C., Pannikar, B., and Pannikar, K.R. (1991a). Antitumor activity of saffron (Crocus sativus). Cancer Lett 57, 109-114.

Nair, S.C., Salomi, M.J., Panikkar, B., and Panikkar, K.R. (1991b). Modulatory effects of Crocus sativus and Nigella sativa extracts on cisplatin-induced toxicity in mice. J Ethnopharmacol 31, 75-83.

Nair, S.C., Varghese, C.D., Pannikar, K.R., Kurumboor, S.K., and Parathod, R.K. (1994). Effect of saffron on vitamin A levels and its antitumor activity on the growth of solid tumors in mice. Int J Clin Pharmacol 32, 105-114.

Ochiai, T., Ohno, S., Soeda, S., Tanaka, H., Shoyama, Y., and Shimeno, H. (2004a). Crocin prevents the death of rat pheochromyctoma (PC-12) cells by its antioxidant effects stronger than those of alpha-tocopherol. Neurosci Lett 362, 61-64.
Ochiai, T., Shimeno, H., Mishima, K., Iwasaki, K., Fujiwara, M., Tanaka, H., Shoyama, Y., Toda, A., Eyanagi, R., and Soeda, S. (2007). Protective effects of carotenoids from saffron on neuronal injury in vitro and in vivo. Biochim Biophys Acta 1770, $578-584$.

Ochiai, T., Soeda, S., Ohno, S., Tanaka, H., Shoyama, Y., and Shimeno, H. (2004b). Crocin prevents the death of PC-12 cells through sphingomyelinase-ceramide signaling by increasing glutathione synthesis. Neurochem Int 44, 321-330.

Papandreou, M.A., Kanakis, C.D., Polissiou, M.G., Efthimiopoulos, S., Cordopatis, P., Margarity, M., and Lamari, F.N. (2006). Inhibitory activity on amyloid-beta aggregation and antioxidant properties of Crocus sativus stigmas extract and its crocin constituents. J Agric Food Chem 54, 8762-8768.

Pham, T.Q., Cormier, F., Farnworth, E., Tong, V.H., and Van Calsteren, M.R. (2000). Antioxidant properties of crocin from Gardenia jasminoides Ellis and study of the reactions of crocin with linoleic acid and crocin with oxygen. J Agric Food Chem 48, 1455-1461.

Pitsikas, N., Zisopoulou, S., Tarantilis, P.A., Kanakis, C.D., Polissiou, M.G., and Sakellaridis, N. (2007). Effects of the active constituents of Crocus sativus L., crocins on recognition and spatial rats' memory. Behav Brain Res 183, 141-146.

Premkumar, K., Abraham, S.K., Santhiya, S.T., Gopinath, P.M., and Ramesh, A. (2001). Inhibition of genotoxicity by saffron (Crocus sativus L.) in mice. Drug Chem Toxicol 24, 421-428.

Premkumar, K., Abraham, S.K., Santhiya, S.T., and Ramesh, A. (2003). Protective effects of saffron (Crocus sativus L.) on genotoxins-induced oxidative stress in Swiss albino mice. Phytother Res 17, 614-617.

Premkumar, K., Thirunavukkarasu, C., Abraham, S.K., Santhiya, S.T., and Ramesh, A. (2006). Protective effect of saffron (Crocus sativus L.) aqueous extract against genetic damage induced by anti-tumor agents in mice. Hum Exp Toxicol 25, 79-84.

Rios, J.L., Recio, M.C., Ginger, R.M., and Manz, S. (1996). An update review of saffron and its active constituents. Phytother Res 10, 189-193.

Rogers, A.E., Zeisel, S.H., and Groopman, J. (1993). Diet and carcinogenesis. Carcinogenesis 14, 2205-2217.

Saleem, S., Ahmad, M., Ahmad, A.S., Yousuf, S., Ansari, M.A., Khan, M.B., Ishrat, T., and Islam, F. (2006). Effect of saffron (Crocus sativus) on neurobehavioral and neurochemical changes in cerebral ischemia in rats. J Med Food 9, 246-253.

Salomi, M.J., Nair, S.C., and Panikkar, K.R. (1991a). Cytotoxicity and non-mutagenicity of Nigella sativa and saffron (Crocus sativus) in vitro. Proc Ker Sci Congr 5, 244.

Salomi, M.J., Nair, S.C., and Panikkar, K.R. (1991b). Inhibitory effects of Nigella sativa and saffron (Crocus sativus) on chemical carcinogenesis in mice. Nutr Cancer 16, 67-72.

Sasaki, Y.F., Izumiyama, F., Nishidate, E., Matsusaka, N., and Tsuda, S. (1997a). Simple detection of chemical mutagens by the alkaline single-cell gel electrophoresis (comet) assay in multiple mouse organs (liver, lung, spleen, kidney, and bone marrow). Mutat Res 391, 215-231.

Sasaki, Y.K., Tsuda, S., Izumiyama, F., and Nishidate, E. (1997b). Detection of chemically induced DNA lesions in multiple mouse organs (liver, lung, spleen, kidney, and bone marrow) using the alkaline single cell gel electrophoresis (comet) assay. Mutat Res 388, 33-44.

Sekihashi, K., Yamamotoa, A., Matsumura, Y., Uenob, S., Watanabe-Akanuma, M., Kassie, F., Knasmüller, S., Tsuda, S., and Sasaki, Y.F. (2002). Comparative investigation of multiple organs of mice and rats in the comet assay. Mutat Res 517, 53-74. 
Shen, X.C., and Qian, Z.Y. (2006). Effects of crocetin on antioxidant enzymatic activities in cardiac hypertrophy induced by norepinephrine in rats. Pharmazie 61, 348-352.

Soeda, S., Ochiai, T., Paopong, L., Tanaka, H., Shoyama, Y., and Shimeno, H. (2001). Crocin suppresses tumor necrosis factoralpha-induced cell death of neuronally differentiated PC-12 cells. Life Sci 69, 2887-2898.

Tarantilis, P.A., Morjani, H., Polissou, M., and Manafait, M. (1994). Inhibition of growth and induction of differentiation of promyelocytic leukemia (HL-60) by carotenoids from Crocus sativus L. Anticancer Res 14, 1913-1918.

Tarantilis, P.A., Tsoupras, G., and Polissiou, M. (1995). Determination of saffron (Crocus sativus L.) components in crude plant extract using high performance liquid chromatographyUV-visible photodiode-array detection-mass spectrometry. J Chromatogr A 699, 107-118.

Tseng, T.H., Chu, C.Y., Huang, J.M., Shiow, S.J., and Wang, C.J. (1995). Crocetin protects against oxidative damage in rat primary hepatocytes. Cancer Lett 97, 61-67.

Tsuda, S., Matsusaka, N., Madarame, H., Miyamae, Y., Ishida, K., Satoh, M., Sekihashi, K., and Sasaki, Y.F. (2000). The alkaline single cell electrophoresis assay with eight mouse organs: results with 22 mono-function alkylating agents (including 9 diakyl-nitrosoamines) and 10 DNA cross linkers. Mutat Res 467, 83-98.

Verma, S.K., and Bordia, A. (1998). Antioxidant property of saffron in man. Indian J Med Sci 52, 205-207.
Wang, C.J., Hsu, J.D., and Lin, J.K. (1991a). Suppression of aflatoxin B1-induced hepatotoxicity lesions by crocetin. Carcinogenesis 12, 1807-1810.

Wang, C.J., Lee, M.J., Chang, M.C., and Lin, J.K. (1995). Inhibition of tumor promotion in benzo(a)pyrene-initiated CD-1 mouse skin by crocetin. Carcinogenesis 16, 501-506.

Wang, C.J., Shiow, S.J., and Lin, J.K. (1991b). Effects of crocetin on the hepatotoxicity and hepatic DNA binding of aflatoxin $B_{1}$ in rats. Carcinogenesis 12, 459-462.

Zheng, Y.Q., Liu, J.X., Wang, J.N., and Xu, L. (2007). Effects of crocin on reperfusion-induced oxidative/nitrative injury to cerebral microvessels after global cerebral ischemia. Brain Res 1138, 86-94.

Address reprint requests to: Hossein Hosseinzadeh, Pharm.D., Ph.D. Pharmaceutical Research Center School of Pharmacy Mashhad University of Medical Sciences Mashhad 1365-91775 I.R. Iran

E-mail: hosseinzadehh@mums.ac.ir

Received for publication May 21, 2008; received in revised form July 23, 2008; accepted July 23, 2008. 